wWw.volsu.ru

DOI: https://doi.org/10.15688/nsr.jvolsu.2019.1.6

UDC 504.062

LBC $26.23+67.401$ я73 M 69

\title{
RESEARCH OF THE CONDITIONS OF PRESERVATION OF THE SOIL MASS DURING CONSTRUCTION WORKS
}

\author{
Marina V. Trokhimchuk \\ Volgograd State University, Volgograd, Russian Federation \\ Margarita V. Postnova \\ Volgograd State University, Volgograd, Russian Federation \\ Katerina A. Trokhimchuk \\ Volgograd State University, Volgograd, Russian Federation
}

\begin{abstract}
The paper shows that the fulfillment of construction works influences the level of fine dust content in urban environment. Investigations of fine dust emissions in the zones of earth excavations and soil spoil banks caused by construction works were carried out. The authors conducted an integrated investigation of the physicochemical processes in the surface layer of the atmosphere in the course of construction works, which was based on the field and computational experiments. With the help of a laboratory wind-tunnel plant, it was revealed that the character of dust emission during the development of dispersive massifs depends on the climatic conditions, in particular on the wind velocity and the physical-and-mechanical properties of the rocks (humidity, porosity, plasticity indices). A specific-purpose GIS application has been designed which allows modelling the dynamics of air flows in the territories with anthropogenic development. The application is based on the methods of mathematical and simulation modelling, the methods of visualization and surface plotting as well as the methods of software applications development.
\end{abstract} packages.

Key words: dust emission, atmospheric pollutants, soil massif, geo-information technologies, modelling

УДК 504.062

\section{ИССЛЕДОВАНИЕ УСЛОВИЙ СОХРАНЕНИЯ ГРУНТОВОГО МАССИВА ПРИ ПРОВЕДЕНИИ СТРОИТЕЛЬНЫХ РАБОТ}

\author{
Марина Викторовна Трохимчук \\ Волгоградский государственный университет, г. Волгоград, Российская Федерация \\ Маргарита Викторовна Постнова \\ Волгоградский государственный университет, г. Волгоград, Российская Федерация \\ Катерина Алексеевна Трохимчук \\ Волгоградский государственный университет, г. Волгоград, Российская Федерация
}

Аннотация. Показано, что проведение строительных работ влияет на степень запыленности мелкодисперсной пылью городской среды. Проведены исследования выделения мелкодисперсной пыли в зонах земляных выемок, грунтовых и строительных отвалов. Выполнено комплексное исследование физико-химических процессов в приземном слое атмосферы при строительных работах, построенное на натурном и вычислительном эксперименте. С помощью лабораторной аэродинамической трубы выявлено, что характер выде- 


\section{ЭКОЛОГИЯ И ПРИРОДОПОЛЬЗОВАНИЕ}

ления пыли при разработке дисперсных массивов зависит от климатических условий, в частности, скорости ветра и физико-механических свойств пород (влажности, пористости, показателей пластичности). Создано специализированное ГИС-приложение, позволяющее моделировать динамику воздушных потоков на территориях с антропогенной застройкой, в основу которого положены методы математического и имитационного моделирования, методы визуализации и построения поверхностей, методы разработки программных приложений.

Ключевые слова: пылевыделение, атмосферные загрязнения, грунтовый массив, геоинформиционные технологии, моделирующие комплексы.

Постановка проблемы. В процессе проведения строительных работ происходит загрязнение атмосферного воздуха частицами пыли различных фракций. При этом наиболее пылящим является технологический процесс устройства котлована, траншеи, выемки. включающий разработку грунта с выгрузкой в транспортные средства или на бровку котлована или траншеи, где формируется строительный отвал, сложенный из природного грунта. Также на строительной площадке накапливается строительный отход. Грунтовые и строительные массивы подвергаются климатическому воздействию, в частности интенсивной ветровой нагрузке, где наиболее подверженными данным условиям являются дисперсные породы. Происходит загрязнение атмосферного воздуха частицами различных фракций. Как отмечает целый ряд исследователей, наиболее опасными для жизнедеятельности человека являются мелкодисперсные частицы с размерами менее 2,5 мкм $\left(P M_{2,5}\right)$ и не более 10 мкм $\left(P M_{10}\right)$, образующиеся в большом процентном составе у дисперсных грунтов. Поэтому на сегодняшний день важной задачей является исследования процесса движения пылевоздушных потоков на территориях с антропогенной застройкой. Поскольку наиболее полным исследованием для любых физико-химических процессов в приземном слое атмосферы является комбинация натурного и вычислительного эксперимента $[13 ; 15 ; 20 ; 21]$, то данная работа также выполнялась по этому принципу.

Исследование дисперсного состава пылевого аэрозоля, поведения пылевых частиц в условиях внешних воздействий, исследование ряда задач, связанных со снижением концентрации пыли в окружающей среде, совершенствование техники обеспыливания нашло отражение в работах В.Н. Азарова [1-9; 19],
Н.Я. Авдеев, В.И. Беспалова, Е.И. Богуславского, В.Е. Глузберга, Н.Ф. Гращенкова, В.В. Дьякова, В.К. Журавлева, В.П. Журавлева, Г.С. Забурдяева, И.Г. Ищука, Б.Ф. Кирина, Ф.С. Клебанова, П.А. Коузов, В.В. Кудряшова, И.Ф. Ливчака, И.Н. Логачева, К.И. Логачева, С.И. Луговского, А.Б. Лукьянова, Е.П. Медникова, М.А. Менковского, Н.В. Мензелинцевой, В.А. Минко, В.С. Никитина, Н.В. Перцева, Г.А. Позднякова, Г.И. Ромашов, В.И. Саранчука, В.Ф. Сидоренко, Н.А. Страховой, А.А. Цыцуры, Л.А. Шварцмана, М.И. Шиляева, Е.А. Штокмана и др. авторов. В связи с развитием городов в мировой практике появился целый ряд исследований, касающихся загрязнений атмосферного воздуха мелкодисперсной пылью [11; 12; 14; 18; 22; 23; 24]. Можно выделить работы следующих исследователей: Б. Барратта, Р. Бурки, Д. Грина, В. Гросса, И. Гулда, Р. Ларсена, Х. Лонга, А. Маккея, П. Моргенштерн, Т. Окита, Т. Руана, Н. Розе, Г. Фуллера, С. Юнге. Из зарубежных авторов, занимающихся вопросами атмосферной диффузии, следует отметить в первую очередь работы О.Г. Сеттона. Эти вопросы рассматривались также в работах D. Carslaw [10], Р. Маккортина, Е. Хьюстона, Г. Хольцворта, М. Хиго. Вопрос пылевого загрязнения воздушной среды городов при земляных работах в строительстве изучен слабо, особенно это относится к мелкодисперсной пыли.

Цель исследования: изучение процесса динамики воздушных потоков у дисперсных горных пород, задействованных при земляных работах путем проведения натурного и вычислительного эксперимента.

Материал и методы исследования. Для натурного эксперимента использована лабораторная аэродинамическая труба, представляющая собой установку для получения в рабочей части трубы искусственного равномерного прямолинейного потока воздуха, 
имитирующего действие ветра. Опыты в аэродинамической трубе основываются на принципе обратимости движения, когда движение воздуха набегает на неподвижное тело. Для моделирования движения тела в покоящемся воздухе в аэродинамической трубе создается равномерный поток, имеющий в любых точках равные и параллельные скорости (равномерное поле скоростей), одинаковые плотность и температуру. В качестве побудителя движения воздуха используются два осевых вентилятора мощностью 110 Вт и совершающих 1400 оборотов в минуту (рис. 1). Аэродинамическая труба снабжена панелью управления и соединена с компьютером, имеющим программное обеспечение, позволяющее задавать и фиксировать скорость потока воздуха, время проведения эксперимента, характер работы вентиляторов. Исследованы наиболее распространенные дисперсные грунты территории городов Нижнего Поволжья: верхнечетвертичные лессовые породы валдайского горизонта; морские нижнехвалынские глины (образцы взяты из выветрелой поверхностной толщи и зоны природного естественного залегания); современные аллювиальные супеси; техногенный грунт. Дисперсный состав пыли определялся по методике с использованием оптической микроскопии и программы «Dust».

В вычислительном эксперименте использованы геоинформационные технологии и методы решения задач по моделированию динамики распространения загрязняющих веществ.

В течение 2018 г. в летнее и осеннее время в городе Волгограде были проведены за- меры концентрации мелкодисперсной пыли $P M_{10}$, в рамках мониторинга загрязнения воздушной среды. Измерения проводились прибором Air pointe, при этом одновременно измерялись еще три фактора: скорость ветра (м/с), влажность (\%) и температура (в градусах С) воздуха. В летние месяцы измерения проводились в течение 66 дней, в осенние месяцы в течение 65 дней. Как показали измерения, число превышений концентрации твердых частиц $P M_{10}$ нормы для летних месяцев составляет 48 дней, а для осенних - 51 день.

Результаты и их обсуждение. В результате проведенного эксперимента получено, что наиболее неустойчивым к ветровой нагрузке грунтом является техногенная порода, имеющая неоднородный состав и высокий процент пылеватой фракции. Весовая доля пылевой фракции колеблется от 2,34 до 4,89 \% и зависит от интенсивности ветра.

Верхнечетвертичные лессовые породы валдайского горизонта и современные аллювиальные супеси также склонны к пылевыделению, особенно при высоких скоростях ветрового потока. Весовая доля пылевой фракции данных дисперсных грунтовых массивов составляет от 1,12 до $2,35 \%$ от двух килограммовой навеки (100\%), что связано с особенностями гранулометрического состава грунтов и физико-механическими свойствами. К наименее пылевыделяющим грунтам относятся морские нижнехвалынские глины, весовая доля пылевой фракции которых колеблется от 0,05 до $1,94 \%$. Они являются более плотными и влажными, характеризуются высоким процентным содержанием глинистых минералов. Отмечена повы-

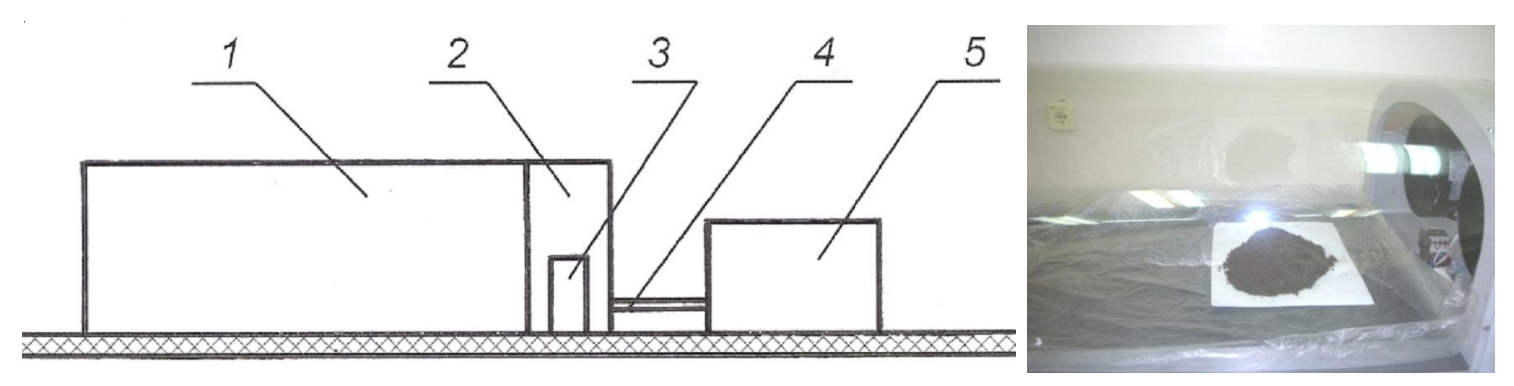

Рис. 1. Схема лабораторной аэродинамической трубы:

1 - прямоточный воздуховод; 2 - отсек с двумя осевыми вентиляторами; 3 - панель управления; 4 - блок соединения с компьютером; 5 - компьютер 


\section{ЭКОЛОГИЯ И ПРИРОДОПОЛЬЗОВАНИЕ}

шенная степень пылевыделения у морских нижнехвалынских глин в верхней, выветрелой поверхностной толще, имеющей более низкие показатели влажности и плотности. Кроме того, процесс выветривания глин сопровождается возникновением вторичных минералов, хорошо подверженных интенсивному пылевыделению.

Анализ существующих программных комплексов для моделирования динамики воздушных потоков показал, что они опираются на стандартные методы вычислительной гидродинамики: метод конечных элементов для несжимаемой жидкости и методы интегрирования уравнений Навье-Стокса для вязкой несжимаемой жидкости [16; 17]. Основной функционал программного комплекса распределяется следующим образом: интерфейс пользователя осуществляет контроль над всей геоинформационной системой; модуль работы с картой содержит функции открытия карты, добавления, удаления существующих зданий, строительных объектов и отображения карты пользователю; модуль визуализации 3D отвечает за построение 3D модели рельефа; расчетный модуль (включает в себя: а) блок расчета динамики примесей и аэрозолей, решающий уравнение диффузии по численным схемам; б) блок «Газовая динамика» является внешним подключаемым модулем).

Разработанная информационная модель специализированной ГИС для моделирования динамики воздушных потоков предоставляет пользователям такие возможности как:

a) работу с картографическими данными, в частности, с картами рельефа местности в форматах 2D и 3D в различных вариантах отображения карты и объектов на карте;

б) выбор участка территории в любом масштабе, нанесение на карту существующих сооружений, объектов строительства и других конструкций;

в) экспорт карт в формат .grd;

г) построение срезов поверхности по выделенной траектории;

д) расчет динамики воздушных потоков и распространения загрязняющих примесей на территориях строительства в зонах с антропогенной застройкой осуществ- ляется по двум методам: с использованием явной и неявной численных схем. Если выбранный пользователем метод не является оптимальным для данного расчета, система извещает об этом пользователя и предлагает провести расчет по другому методу. Проверка оптимальности решения по выбранной численной схеме осуществляется по условию:

$$
\frac{h}{\vec{V}}>\delta \frac{h^{2}}{2 D},
$$

где $\delta=3$, если данное условие выполняется, то используется неявная численная схема.

е) визуализация произведенных расчетов путем построения 2D и $3 \mathrm{D}$ моделей (рис. 2).

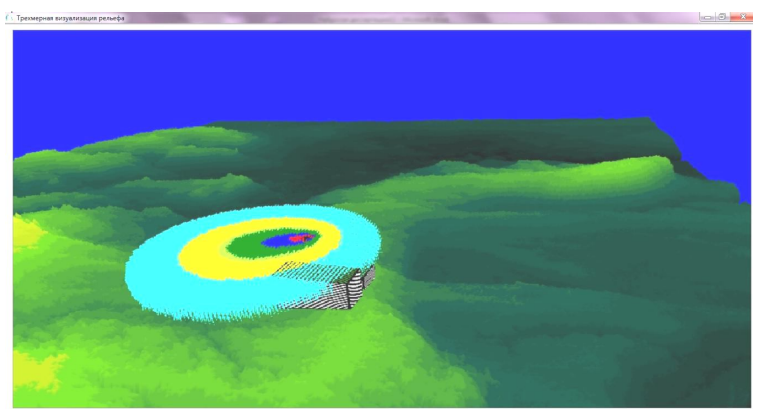

Рис. 2. Расчет распространения примеси. Ветер восточный

Известно, что максимальную суточную концентрацию пыли $C(t)$ можно рассматривать как случайную функцию нормального стационарного процесса. Для закона распределения максимальной суточной концентрации пыли $P M_{10}$ в летние и осенние месяцы города Волгограда были определены его вид и параметры.

По виду гистограмм распределения (см. рис. 3), на основании анализа выборочных данных и оценок параметров распределения можно предположить, что имеет место нормальный или логарифмически-нормальный законы для максимальной суточной концентрации пыли. Проверка предположений о нормальном и логнормальном законах распределения осуществлялась с помощью критериев Хи-квадрат и Колмогорова-Смирнова при уровне значимости $\alpha=0,05$. Вся выборка была разбита на 10 групп. Результаты вычисленных статистик отображены в таблице 1. 
По таблице критических точек Хи-квадрат по заданному уровню значимости $\alpha=0,05$ и числу степеней свободы $k=7$ была найдена критическая точка $\chi_{\mathrm{kp}}^{2}=14,067$. Так как для нормального закона в обоих случаях $\chi^{2}>\chi_{\mathrm{kp}}^{2}$, то гипотеза о нормальном законе максимальной суточной концентрации пыли не согласуются с опытными данными. В то же время для логарифмического нормального закона выполняется требование $\chi^{2}<\chi_{\mathrm{kp}}^{2}$, и, следовательно, этот закон согласуется с опытными данными.

Для применения критерия КолмогороваСмирнова была вычислена величина $\lambda=d \sqrt{n}$ (см. табл. 1). По таблице критических точек Колмогорова определили критическое значение $\lambda_{0}=1,63$. Так как $\lambda<\lambda_{0}$ только для логнормального закона, то на уровне значимости $\alpha=0,05$ гипотеза о логнормальном законе также согласуются с опытными данными. Следовательно, по обоим критериям логнормальный закон можно использовать для описания максимальной суточной концентрации пыли. Таким образом, были определены функция плотности $f(C)$ и интегральная функция $F(C)$

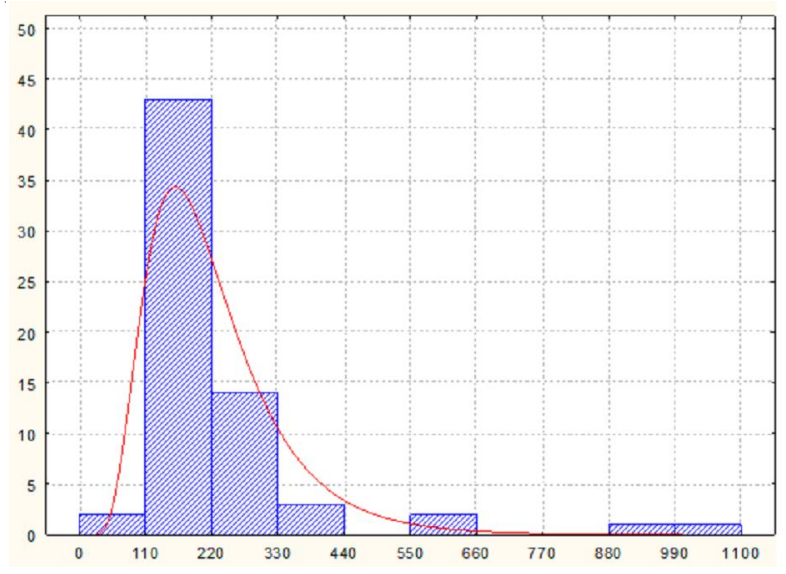

$a$ логнормального распределения для максимальной суточной концентрации пыли.

Для оценки зависимости $P M_{10}$ от трех факторов (скорости ветра, влажности и температуры воздуха) все исходные данные были приведены к нормированному виду. Были введены в рассмотрение следующие переменные: $Y_{j}$ - концентрация взвешенных частиц $P M_{10}$; $X_{1 \mathrm{j}}$ - скорость ветра; $X_{2 \mathrm{j}}$ - влажность; $X_{3 \mathrm{j}}$ температура воздуха в $j$-ый день. Нормирование осуществлялось по формулам:

$$
\begin{gathered}
y_{j}=\frac{Y_{j}-Y_{0}}{\Delta y} ; \\
x_{i}=\frac{X_{i j}-X_{i 0}}{\Delta x_{i}} ; \\
X_{i 0}=\frac{\max _{j}\left\{X_{i j}\right\}+\min _{j}\left\{X_{i j}\right\}}{2} ; \\
\Delta x_{i}=\frac{\max _{j}\left\{X_{i j}\right\}-\min _{j}\left\{X_{i j}\right\}}{2},
\end{gathered}
$$

$i=1,2,3 ; j=1 \div 65$.

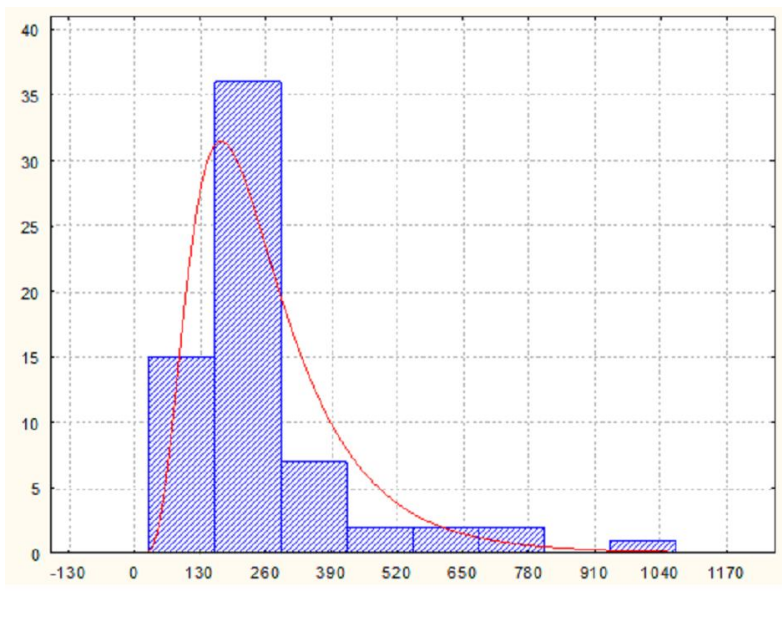

6

Рис. 3. Гистограмма и теоретическая кривая распределения максимальной суточной концентрации пыли г. Волгограда:

$a$ - летние месяцы; $\sigma$ - осенние месяцы

Таблица 1

Значения статистик по выборке

\begin{tabular}{|c|l|c|c|c|}
\hline \multirow{2}{*}{ Время года } & \multicolumn{1}{|c|}{ Закон } & \multicolumn{2}{|c|}{ Значения статистик } \\
\cline { 3 - 5 } & распределения & Хu-квадрат & \multicolumn{2}{|c|}{ Колмогорова-Смирнова } \\
\cline { 3 - 5 } & & $\chi^{2}$ & $d$ & \multicolumn{1}{c|}{$\lambda$} \\
\hline Летние месяцы & Нормальный & 60,61485 & 0,20256 & 0,802411 \\
& Логнормальный & 9,1588 & 0,09877 & 1,845048 \\
\hline \multirow{2}{*}{ Осенние месяцы } & Нормальный & 29,3167 & 0,22885 & 0,944493 \\
& Логнормальный & 6,1655 & 0,11715 & \\
\hline
\end{tabular}




\section{ЭКОЛОГИЯ И ПРИРОДОПОЛЬЗОВАНИЕ}

Для каждого месяца исследовались линейная и квадратическая регрессия, то есть уравнение регрессии отыскивалось в двух видах:

$$
y=b_{0}+b_{1} x_{1}+b_{2} x_{2}+b_{3} x_{3}
$$

И

$$
y=b_{0}+b_{1} x_{1}^{2}+b_{2} x_{2}^{2}+b_{3} x_{3}^{2}+b_{4} x_{1} x_{2}+b_{5} x_{1} x_{3}+b_{6} x_{2} x_{3} .
$$

Уравнения регрессии были получены при следующих исходных данных (табл. 2).

Как показали результаты расчетов для июня и августа месяца на основе $F$ - критерия Фишера наиболее целесообразна квадратичная модель, а для остальных месяцев линейная модель. При этом универсальную форму зависимости загрязнения $P M_{10}$ в атмосфере города Кабула от трех факторов: скорости ветра, влажности и температуры воздуха получить одновременно для всех сезонных месяцев не удается, так как ни одна модель не дает хороший коэффициент корреляции. Однако для каждого месяца такие зависимости были получены и уравнения регрессии представлены в таблице 3.

Выводы. Программно реализован управляющий модуль «AirFlowBuild», включающий в себя интерфейс приложения и модуль для работы с картой и её объектами. Реализован модуль визуализации 2D и 3D карт и расчетов, который позволяет строить двух- и трехмерную модель рельефа местности в раз- личных вариантах отображения карты и объектов на карте. Разработан расчетный модуль, позволяющий моделировать динамику распространения примесей и аэрозолей с учетом внешних нестационарных факторов.

Можно утверждать, что распределение концентрации мелкодисперсной пыли в летние и осенние месяцы подчинено логарифмическому нормальному закону. Коэффициент корреляции для всех летних месяцев и ноября говорит о заметной тесноте связи, в сентябре и октябре - о высокой тесноте связи между $P M_{10}$, скоростью ветра, влажностью и температурой воздуха. При этом оказалось, что в июне и июле определяющими параметрами являются скорость ветра и влажность.

\section{СПИСОК ЛИТЕРАТУРЫ}

1. Гигиенические нормативы ГН 2.1.6.2604-10 «Предельно допустимые концентрации (ПДК) загрязняющих веществ в атмосферном воздухе населенных мест». - М.: Минздрав России, 2010. -61 с.

2. Заде, Г. О. Химический состав атмосферного аэрозоля на различных высотах / Г. О. Заде, Б. Д. Белан Т. В. Ковалевская // Фотохимические процессы земной атмосферы : сб. науч. тр. - М. : Наука, 1990. - С. 5-12.

3. Методика микроскопического анализа дисперсного состава пыли с применением персонального компьютера. - СПб. : НИИ Атмосфера, 2013.C. 15-17.

Таблица 2

Значения переменных для нормирования

\begin{tabular}{|c|c|c|c|c|}
\hline \multirow{2}{*}{ Переменные } & \multicolumn{2}{|c|}{ Значения переменных $Y_{0}, X_{i 0}$} & \multicolumn{2}{c|}{ Интервалы изменения $\Delta y, \Delta x_{i}$} \\
\cline { 2 - 5 } & Летние месяцы & Осенние месяцы & Летние месяцы & Осенние месяцы \\
\hline$Y$ & 550,5 & 522,5 & 450,5 & 486,5 \\
$X_{1}$ & 3,5 & 3,5 & 3,5 & 3,5 \\
$X_{2}$ & 23 & 39,5 & 18 & 33,5 \\
$X_{3}$ & 32,5 & 17,5 & 4,5 & 12,5 \\
\hline
\end{tabular}

Уравнения регрессии для $P M_{10}$

Таблица 3

\begin{tabular}{|l|c|c|}
\hline \multicolumn{1}{|c|}{ Месяц } & Уравнение регрессии & $\begin{array}{c}\text { Множественный коэф- } \\
\text { фициент корреляции } R\end{array}$ \\
\hline Июнь & $y=-0,8979+0,1061 x_{1} x_{2}$ & 0,621 \\
Июль & $y=-0,7167+0,0585 x_{1}+0,1497 x_{2}-0,0219 x_{3}$ & 0,615 \\
Август & $y=-0,4787-0,7569 x_{1}^{2}+0,8442 x_{2}^{2}-0,2698 x_{3}^{2}-0,4763 x_{2} x_{3}$ & 0,614 \\
Сентябрь & $y=-0,0578 x_{1}+0,9470 x_{2}+0,1123 x_{3}$ & 0,98 \\
Октябрь & $y=-0,3423-0,1340 x_{1}+0,6375 x_{2}+0,1565 x_{3}$ & 0,75 \\
Ноябрь & $y=0,7810 x_{1}-0,1922 x_{2}-0,0097 x_{3}$ & 0,56 \\
\hline
\end{tabular}


4. Методика расчета концентраций в атмосферном воздухе вредных веществ, содержащихся в выбросах предприятий: ОНД-86/ Госкомгидромет СССР : Введ. 01.01.87; Взамен СН369-74. - Л. : Гидрометеоиздат, 1987.- $91 \mathrm{c.}$

5. Методическое пособие по расчету выбросов от неорганизованных источников в промышленности строительных материалов. - Новороссийск : НИПИОТСТРОМ, 2002. - 28 с.

6. Пат. 32787 Российская Федерация. Машина для уборки дорожных покрытий / Завьялов Ю. И. ; заявитель и патентообладатель Общество с ограниченной ответственностью «Планета-К». - Заявл.14.05.2003 ; опубл. 27.09.2003.-М. : ФИПС. 2003. C. 1-3.

7. Пат. 2147640 Российская Федерация. Машина для очистки твердых поверхностей / Закревский В. А., Соломянский В. Б., Ростовцев Д. М. ; заявитель и патентообладатель Научно-производственное товарищество с ограниченной ответственностью «Русская керамика». - Заявл. 17.02.1998; опубл. 20.04.2000.- М. : ФИПС. 2000.- С. 1-5.

8. Пат. 2025555 Российская Федерация. Подборщик подметально-уборочной машины / Свидинский А. П., Стельмашенко А. И., Бобров А. Г. ; заявитель и патентообладатель Научно-производственное объединение строительного и коммунального машиностроения «Стройкоммаш». - Заявл. 03.06.1991 ; опубл. 30.12.1994.- М. : ФИПС. 1994.-С. 1-4.

9. Пат. 2014136502 Российская Федерация. Пылезащитное устройство в строительстве / Трохимчук К. А. [и др.] ; заявитель и патентообладатель Волградский государственный университет. - Заявл. 08.09.2014; опубл. 20.02.2015; Бюл. № 5. - М. : ФИПС. 2015. - 6 с

10. Пат. 2014136502 Российская Федерация. Пылезащитное устройство в строительстве / Трохимчук М. В. [и др.] ; заявитель и патентообладатель Волградский государственный университет. Заявл. 08.09.2014 ; опубл. 20.02.2015 ; Бюл. № 5. М. : ФИПС. 2015. -6 c.

11. Сергина, Н. М. Методика микроскопического анализа дисперсионного состава пыли с применением персонального компьютера (ПК) / Н. М. Сергина, В. Н. Азаров, В. Ю. Юркъян // Законодательная и прикладная метрология. - 2004. № 1. - С. 46-48.

12. Экология города / под ред. И. В. Стольберга : учебник. - Киев : Либра, 2000. - 213 с.

13. Энциклопедический словарь юного химика. - М. : Педагогика, 1990. - 320 с.

14. Янди, К. В. Смог над городом. - М. : Стройиздат, 1978. - $109 \mathrm{c}$.

15. Яшек, Е. П. Промышленная пыль в городской среде (геохимические особенности и экологическая оценка). - М. : ИМ ГРЭ, 2003. - 82 с.
16. Evaluation of the impact of dust suppressant application application on ambient PM 10 concentrations in London / B. Barratt, D. Carslaw, D. Green, G. Fuller, A. Tremper // King's College London, Environmental Research Group Prepared for Transport for London under contractto URS Infrastructure \& Environment Ltd. - London : Noyes Data Corp., 2012. - P. 234-286.

17. Directive 2008/50/EC of the European Parliament and of the Councul of 21 May 2008 on ambient air gualitu and cleaner air for Europe // Official Journal of the European Union. - Hungary : Patent Office. - 2008. - June, 11. - P. 1-4.

18. Extensive Dachbegrünung. Ergebnisse des Symposiums in der Technischen Universität Berlin. Berlin : M. Köhler, 1990.-124 s.

19. Hupfer, P. Witterung und Klima / P. Hupfer, W. Kuttler.-Stuttgart, Leipzig:B.G.Teubner, 1998. - 167 s.

20. Köhler, M. Hof-, Fassaden- und Dachbegrünung Zentraler Baustein der Stadtökologie / M. Köhler, M. Schmidt. - Berlin, Maple, 1997. - 178 s.

21. New approaches to characterizing urban air partickles in central London / A.W. Mackay, X. Long, N. L. Rose, R.W. Battarbee// J. Environ. Sei. (China). Beijing : Cub, 1999. - № 3. - P. 367-372.

\section{REFERENCES}

1. Gigienicheskie normativy GN 2.1.6.2604-10 "Predelno dopustimye koncentracii (PDK) zagrjaznjajushhih veshhestv $v$ atmosfernom vozduhe naselennyh mest». Moscow, Minzdrav Rossii, 2010. $61 \mathrm{p}$.

2. Zade G.O., Belan B.D., Kovalevskaja T.V. Himicheskij sostav atmosfernogo ajerozolja na razlichnyh vysotah. Fotohimicheskie processy zemnoj atmosfery : sb. nauch. tr. Moscow, Nauka, 1990, pp. 5-12.

3. Metodika mikroskopicheskogo analiza dispersnogo sostava pyli s primeneniem personalnogo kompjutera. Saint-Petersburg, NII Atmosfera, 2013, pp.15-17.

4. Metodika rascheta koncentracij $\mathrm{v}$ atmosfernom vozduhe vrednyh veshhestv, soderzhashhihsja v vybrosah predprijatij: OND-86. Goskomgidromet SSSR: Vved. 01.01.87. Saint-Petersburg, Gidrometeoizdat, $1987.91 \mathrm{p}$.

5. Metodicheskoe posobie po raschetu vybrosov ot neorganizovannyh istochnikov $v$ promyshlennosti stroitelnyh materialov. Novorossijsk, NIPIOTSTROM, 2002.28 p.

6. Pat. 32787 Rossiyskaya Federatsiya. Mashina dlja uborki dorozhnyh pokrytij. Zavjalov Ju.I. Zajavitel i patentoobladatel Obshhestvo s ogranichennoj otvetstvennostju "Planeta-K". 


\section{ЭКОЛОГИЯ И ПРИРОДОПОЛЬЗОВАНИЕ}

Zajavl.14.05.2003; opubl. 27.09. 2003. Moscow, FIPS, 2003, pp. 1-3.

7. Pat. 2147640 Rossiyskaya Federatsiya. Mashina dlja ochistki tverdyh poverhnostej. Zakrevskij V.A., Solomjanskij V.B., Rostovcev D.M. Zajavitel i patentoobladatel Nauchno-proizvodstvennoe tovarishhestvo s ogranichennoj otvetstvennostju «Russkaja keramika». Zajavl. 17.02.1998; opubl. 20.04.2000. Moscow, FIPS, 2000, pp. 1-5.

8. Pat. 2025555 Rossiyskaya Federatsiya. Podborshhik podmetalno-uborochnoj mashiny. Svidinskij A.P., StelmashenkoA.I., Bobrov A.G. Zajavitel i patentoobladatel Nauchno-proizvodstvennoe obedinenie stroitel'nogo i kommunal'nogo mashinostroenija “Strojkommash". Zajavl. 03.06.1991; opubl. 30.12.1994. Moscow, FIPS, 1994, pp. 1-4.

9. Pat. 2014136502 Rossiyskaya Federatsiya. Pylezashhitnoe ustrojstvo vstroitelstve. Trohimchuk K.A. et. al. ; Zajavitel i patentoobladatel Volgogradskiy gosudarstvenniy universitet. Zajavl. 08.09.2014; opubl.20.02.2015; Bjul. no. 5. Moscow, FIPS, 2015. 6 p.

10. Pat. 2014136502 Rossiyskaya Federatsiya. Pilezaschitnoe ustroistvo v stroitelstve. Trohimchuk M.V. et al.; Zajavitel i patentoobladatel Volgogradskiy gosudarstvenniy universitet Zajavl. 08.09.2014; opubl. 20.02.2015; Bjul. no. 5. Moscow, FIPS, 2015. 6 p.

11. Sergina N.M., Azarov V.N., Yurkyan V.Yu. Metodika mikroskopicheskogo analiza dispersionnogo sostava pyli s primeneniem personalnogo kompjutera (PK) [A technique for microscopic analysis of the dispersion composition of dust using a personal computer (PC)]. Zakonodatelnaja i prikladnaja metrologija [Legislative and applied metrology], 2004, no 1 , pp. 46-48.
12. Stolberga I.V. ed. Jekologija goroda : uchebnik. Kiev, Libra, 2000. 213 p.

13. Jenciklopedicheskij slovar junogo himika. Moscow, Pedagogika, 199. 320 p.

14. Jandi K.V. Smog nad gorodom. Moscow, Strojizdat, 1978. 109 p.

15. Jashek E.P. Promyshlennaja pyl v gorodskoj srede (geohimicheskie osobennosti i jekologicheskaja ocenka). Moscow, IM GRJe, 2003. 82 p.

16. Barratt B., Carslaw D., Green D., Fuller G., Tremper A. Evaluation of the impact of dust suppressant application application on ambient PM 10 concentrations in London. King's College London, Environmental Research Group Prepared for Transport for London under contractto URS Infrastructure \& Environment Ltd. London, Noyes Data Corp., 2012, pp. 234-286.

17. Directive 2008/50/EC of the European Parliament and of the Councul of 21 May 2008 on ambient air gualitu and cleaner air for Europe. Official Journal of the European Union. Hungary, Patent Office, 2008, June, 11, pp. 1-4.

18. Extensive Dachbegrünung. Ergebnisse des Symposiums in der Technischen Universität Berlin. Berlin, M. Köhler, 1990, 124 s.

19. Hupfer P., Kuttler W. Witterung und Klima. Stuttgart, Leipzig, B.G. Teubner, 1998. 167 p.

20. Köhler M., Schmidt M. Hof-, Fassaden- und Dachbegrünung Zentraler Baustein der Stadtökologie. Berlin, Maple, 1997. 178 p.

21. Mackay A.W., Long X., Rose N.L., Battarbee R.W. New approaches to characterizing urban air partickles in central London. J. Environ. Sei. (China), Beijing, Cub, 1999, no. 3, pp. 367-372. 
М.В. Трохимчук, М.В. Постнова, К.А. Трохимчук. Исследование условий сохранения грунтового массива

\section{Information about the Authors}

Marina V. Trokhimchuk, Candidate of Sciences (Geology and Mineralogy), Associate Professor,Department of Bioengineering and Bioinformatics, Volgograd State University, prosp. Universitetskiy, 100, 400062 Volgograd, Russian Federation, tro232957@mail.ru.

Margarita V. Postnova, Doctor of Sciences (Biology), Senior Researcher, Head of the Department Bioengineering and Bioinformatics, Volgograd State University, prosp. Universitetskiy, 100, 400062 Volgograd, Russian Federation, postnova@volsu.ru.

Katerina A. Trokhimchuk, Candidate of Technical Sciences, Graduate Student, Department of Ecology and Nature Resources Management, Volgograd State University, prosp. Universitetskiy, 100, 400062 Volgograd, Russian Federation, tro232957@mail.ru.

\section{Информация об авторах}

Марина Викторовна Трохимчук, кандидат геолого-минералогических наук, доцент кафедры биоинженерии и биоинформатики, Волгоградский государственный университет, просп. Университетский, 100, 400062, г. Волгоград, Российская Федерация, tro232957@mail.ru.

Маргарита Викторовна Постнова, доктор биологических наук, старший научный сотрудник, заведующий кафедры биоинженерии и биоинформатики, Волгоградский государственный университет, просп. Университетский, 100, 400062 г. Волгоград, Российская Федерация, postnova@volsu.ru.

Катерина Алексеевна Трохимчук, кандидат технических наук, магистрант кафедры экологии и природопользования, Волгоградский государственный университет, просп. Университетский, 100, 400062 г. Волгоград, Российская Федерация, tro232957@mail.ru. 